$0:$ water, and although the fluid was retained about four inimutes it caused no pain. After this stools, three, two, and oue, of more solid consistence, were passed, and before the patient left he had not more than one stool daily, and that healthy in appearance. All through the pus was free from smell and quite healthy.

\section{CASE OF DIABETES ; DEATH THIRTY HOURS AFTER FIRST VISIT.}

By ED. GEO. WHITTLE, M.D. LoND., \&c.

SHARING in the general sympathy which the harsh censure of Dr. Blades has evoked from the profession, I am induced to send you the following report.

On Monday, June 25th, I was called to see a man whom I found lying helpless in bed, with his feet hanging over the side and uncovered, as though he had failed in an attempt to get back. He looked about thirty-five years of age, muscular, spare, but not emaciated; his hands and feet were cold and 6 anosed; his breathing was laborious, rapid, and deep; he conld answer questions, but so slowly and with such evident - ffort, that I put no more than were needed to ascertain that he had his mental faculties. The pupils were equal; there was no paralysis, but when the eyelid was raised, it fell back sluggishly. Chest walls were highly resonant, and the respiration was everywhere loud, harsh, and bronchial, expiration being almost as loud and long as inspiration. Heart healthy. Mucous membrane of lips and eyelids red. Tongue dry and brown. Throat dusky red, with vesicular eruption on soft palate. Palse 140 ; temperature $97.8^{\circ}$. Urine (none saved) reported to be healthy in appearance micturition normal. There was neither odema nor anæmia. The case was clearly one of diabetic dyspnoa, running rapidly to a fatal issue. He soon became unconscious, passed his urine in bed, and died on the evening of the next day. I certified without having examined the urine.

The following is the history as obtained from his wife. Had always been healthy and temperate. A year ago he was treated for an attack of diarrhcea, but had had no medical advice since, nor had he missed a day's work (shoeinaking). On June 19th, a week before death, he had sore-thr.at. On the 21 st his wife wished to send for a doctor, but he said there was no need, as his throat was getting better. For some few weeks he had occasionally complained of fatigue, which he attributed to the hot weather. His sight was slightly impaired. This, he thought was due to sitting too closely at work. He worked as usual on the 23rd (Saturday), but in the evening felt tired and drowsy. The next morning he felt as well as usual, but his wife induced him to remain in bed for the sake of rest. He had no symptoms causing anxiety to himself, and it was only on account of his throat that his wife wished him to have medical advice. On the 25 th he arose at 6 A.M., and his wife ohserved that his breathing was short while dressing. About 1.30 P. M. I saw him in the condition above described.

Remarks. - Having the advantage of the knowledge derived from a study of Dr. Blades' case and a paper read by my friend, Dr. E. Mackey, in which the diagnosis between hysteric, uræmic, and diabetic dyspnoea was ably pointed out, I was saved all trouble in diagnosis. To remove all doubt, however, I drew off some mine after death. It contained albumen and sugar in abundance. I am not ashamed to confess that had this man consulted me on the Friday evening before his death he might possibly have left me with his glycosuria undetected. Very few men in general practice examine the urine at a first consultation as a matter of routine; but unless this rule be observed, anyone may overlook an obscure renal affection, acsepting the suggestion of the patient that his malasie is due to overwork, confinement, heat of the weather, \&c. Are we to be held almost criminally responsible in such cases when the inevitable and natural sequence occurs without its having been prematurely announced? Are we who have the most complex and inconstant phenomena of disease to interpret never to be forgiven an oversight? We cannot avoid them. He who asserts that he cannot err must have had but little experience in the practice of medicine, and I should be sorry to trust myself to his infallibility. Are not most cases of glycosuria, as of albuminuria, already chronic when they first come under notice? Is it not often impossible to assert when

they began? The above case will be classed by many as "acute diabetes"; but if I assert that the man may have had glycosuria for many years, who is to prove the contrary? Brighton.

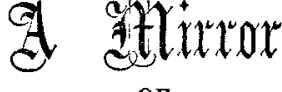

\section{HOSPITAL PRACTICE, BRITISH AND FOREIGN.}

Nu.la autem est alia pro certo noscendi via, nisi quamplurimas et morborum et dissectionum historias, tum aliorum tum proprias collectas habere, et inter se comparare.-MoвqAGNI De Sed, et Caus. Morb., lib. iv. Procmium.

\section{CITY OF LONDON HOSPITAL FOR DISEASES} OF THE CHEST.

MOVABLE TUMOUR IN THE ABDOMEN, SIMULATING MOVABLE KIDNEY; NECROPSY; DISPLACEMENT OF LIVER.

(Under the care of Dr, EUSTACE SMrTH.)

For the notes of the following case, which is of considerable interest from a diagnostic point of view, we are indebted to Mr. T. H. Waller, M.R.C.S., L. R.C.P. Lond., resident medical officer.

J. $\mathrm{S}-$-, aged thirty-four, married, was admitted on June 4th, suffering from advanced phthisis and laryngitis. While in hospital she drew attention to a lump in the right side of her abdomen, which she had noticed for the first time after her last confinement three years previously. It caused her no inconvenience whatever-no pain except on pressure, and then very slight. She had noticed that it often shifted about from one place to another.

On examination, a tumour was felt in the right side of the abdomen, below the margin of the ribs, with the following characters: It was solid, firm, oval in shape, with the long axis parallel with that of the body, and easily movable. When the patient lay on her back, the tumour could be grasped between the thumb and fingers in the right loin, but when she turned on her left side the tumour could be felt in the middle line of the abdomen, returning to its original place immediately the patient lay on her back again. The right kidney could not be felt positively in its natural situation. There was no dulness below the edge of the ribs in the natural position, but when the tumour was pushed forward to the anterior surface of the abdomen, it was found to be dull. The urine was examined several times, and always free from albumen, but contained latterly an abundant deposit of urates. There was no history of any urinary trouble. The tumour was thought undoubtedly to be a "movable kidney." The patient died on July 25 th.

Necropsy. - The right lobe of the liver extended three inches and a half below the level of the ribs, reaching downwards just below the highest point of the erest of the ilium; from its emergence from under the ribs downwards, it nowhere measured more than an inch in thickness. Following the same mode of examination, the movement of this part of the liver corresponded in every way with what had been felt during life : when grasped between the thumb and fingers this part of the liver was folded upon itself, thus giving the tumour the oval shape, and the resemblance to that of the kidney. When removed the liver weighed $48 \mathrm{oz}$, and was healthy. The gall-bladder contained three gallstones, the size of ordinary marbles, with several wellmarked smooth facets on each. The gall-bladder was full, but not distended ; the duct leading from it was occluded, not admitting the largest end of a post-mortem needle further than its entrance. The right kidney was in its natural situation, and healthy.

\section{LEICESTER INFIRMARY.}

NOTES ON A CASE OF HYDROPHOBIA PRESENTING SOME PECULIAR SYMPTOMS ; NECROPSY ; REMARKS.

(Under the care of Dr. CoOpER.)

FOR the following notes we are indebted to $\mathrm{Mr}$. C. J. Bond, F.R.C.S., house-surgeon.

A healthy agricultural labourer, aged fifty-six, was bitten by a large retiliever dog, on Jan. 20th, 1853, on the left 
hand. The wound, or at least one of the scratches, continued in an inflamed discharging state for some time, and, in fact, was only soundly healed fourteen days before admission. The man, however, paid but little attention to it, and went about his work as usual until April 16th, when he began to get rather nervous and fidgety about his hand. On the 19th, on getting up in the morning to go to his work, he felt pain in his chest and some difficulty in breathing, and also in swallowing, and he also vomited ; this nervousness and pain on swallowing increased on this and the following day, and he was admitted into the infirmary on the morning of April 21st, when his condition was noted as follows :- The patient is a strongly made, florid man. He lies quietly in bed, and answers questions quite rationally. He does not attach any importance to the bite, which showrs no signs of redness or inflammation, and has apparently no suspicion of the nature of his disease, though he expresses himself as feeling very ill. Although generally quiet, the noise of falling water poured out, out of his sight, causes him to sit up in bed; his face assumes an anxious, frightened look, the respirations become quick and snatchy, and he implores that no fluid may be given him. When a glass of water is put into his hand and he is asked to drink, he seems agitated, says that he is not afraid of it but cannot drink; he raises the glass a little, then shudders and pushes it away, complaining at the same time of pain at the epigastrium and base of chest. As he lies quietly in bed the respiration is from 16 to 20 per minute; pulse 110, varying somewhat in force and frequency from ime to time, the occurrence of a period of excitement increasing its frequency and lessening its force, and producing irregularity in the rhythm, and intermission occasionally occurring. He is able to open his mouth widely and keep it so when asked, the pupils are equal, and react to light, there are no spasms in the sense of any tonic contraction of any muscle or group of muscles, and the temperature at this time, 11 A.M., is $98^{\circ}$. Urine acid, sp. gr. 1025 ; no albumen. 6.30 $\mathrm{P}_{1} \mathrm{M}_{\text {. : }}$ After several unsuccessful attempts patient has now passed over half a pint of urine, which contains a trace of albumen. The act of micturition caused no spasm or inconvenience to the patient. 7.30 : Patient is now very restless and seems in a jovial mood, he tries to shake hands, kicks off the bedclothes, and as the attacks (that is, the feeling of agitation and oppression, the hurried breathing, and the quickened pulse) come on, he grasps the hand of a bystander, saying that he is thus much relieved; he very frequently spits out frothy saliva very energetically, as though afraid to retain it in his mouth. 12.30 (midnight) : Patient has changed considerably, sits up in bed almost constantly, is still conscious and wishes to see his friends; his face has, however, a very anxious and, at times, a startled expression, and he is constantly spitting out a mixture of frothy, bloodstained mucus and saliva on to the floor, refusing to spit into any vessel. Respiration is now more frequent, and accompanied with bronchial and tracheal râles, and temperature has risen to $99 \cdot 2^{\circ}$ in rectum. - 22nd, 11 A.M. : The mental condition of the patient is gradually more resembling that of mania. His face is flushed; the conjunctivæ suffused. $\mathrm{He}$ is much less sensitive at the approach of strangers, and pays no attention to the sound of falling water, though he still refuses to drink. Water, poured into his mouth, causes no spasm, and he occasionally swallows saliva; the plantar reflexes are abolished; knee-jerk present in both legs, and both testicles are much drawn up. The constant spitting of mucus and saliva continues, though the former is not now blood-stained. The respiratory sounds are clearer, and there is occasional vomiting of a green, bile-stained fluid. The temperature is now, noon, $104 \cdot 4^{\circ}$. 3 P.M. : Patient is now unconscious; his face is very dusky; the romiting of this green fluid is almost constant; pulse very quick and feeble, but regular. At 3.15 P.M. respiration ceased while patient was in the act of vomiting. The temperature in the rectum, forty.eight minutes after death, was $107^{\circ} \mathrm{F}$., and rigor mortis was well marked two hours after death.

At the post-mortem examination it was found impossible in this case, as in previous ones, to assuciate each symptom with a definite pathological lesion. The blood was found coagulated, not fluid as usually described; little or no endocardial blood-staining, so common in septic diseases, and no change which could be called specific was observed by the naked eye in any organ, except that on making sections through the spinal cord and medulla ; the latter and the cord as far as the lower cervical region appeared softer and redder than in the dorsal and lumbar regions. Microscopical ex. amination of the blood at various stages of the disease (by Koch's method) showed nothing abnormal beyond division of the nuclei in the leucocytes and some round deeply stained refractive bodies aggregated together, which might or might not have any specific importance. Examination of the saliva during life, and from a fresh section of the gland immediately after death, showed nothing beyond the usual organisms associated with that secretion when obtained from the mouth. Sections of the sublingual gland stained with logwood showed marked injection of the organ, with numerous granular bodies among the epithelial cells, which resembled leucocytes. Sections of the hardened medulla and cervical cord certainly showed an injected condition of the grey matter, with numerous granules and extravasation of leucocytes around the vessels, as described by Dr. Gowerg. Further, considerable difficulty was experienced in hardening the medulla and cervical portion of the cord in Müller's fluid; not so in the lumbar region.

Remarlis. - In order to correctly estimate the value of the cerebral symptoms in this, as in any case, it is necessary to remember that the patient was a strong, steady farm. labourer, a man in whom the nervous system (as in most men of that class) was previously to the disease in a condition of very stable equilibrium; and although apparently a little nervous about the bite before his illness, he ceased to attach any importance, or to allude to it, after his admission. Regarding the disease as due to some poison acting on the central nervous system, it would seem that in the order of time the respiratory centre was the first to be affected by it, then the cardiac, and, finally, perhaps the vomiting centre. Further, the irregularity and intermission of the pulse, so marked in the early stage, quite passed away before death, and, though cerebral function was much exalted at times, the mental dread of water also quite passed away. Bearing on the selective action of the poison on the medulla is the fact that there was no great radiation of stimulus, no tetanoid spasms, the most marked fit merely resembling the action of a person when getting into a cold bath, together with a superadded emotional condition as though an impression were produced on the respiratory centre like that produced by cold affusion; how far the mental state is one of association or of distinct cerebral poisoning yet remains to be proved. Another feature is that the temperature, said to be usually raised one or two degrees, though normal on admission, rose gradually to $994^{\circ}$ in twelve hours, to $104.4^{\circ}$ in twenty-four hours, and was $107^{\circ}$ in the rectum forty-eight minutes after death.

Any detailed description of the treatment adopted has been purposely avoided, for this case, like every other, shows that we have not yet discovered any specific for hydrophobia ; at the same time the patient was evidently saved a large amount of mental dread and pain from the administration of chloral and morphia in large and frequent doses, the former by rectal injection, the latter by hypodermic injection.

\section{MANCHESTER WORKHOUSE, CRUMPSALL.}

\section{NOTES ON A CASE OF HYSTERICAL (?) HEMT-AN ESTHESIA}

$$
\text { IN A MAN. }
$$

For the following interesting notes we are indebted to Mr. C. B. Voisey, M.R.C.S.

W. M-, a strong and powerful-looking man, was admitted on March 8th, 1883, in such a weak-minded and melancholic condition that it was some days before anything like a rational history could be elicited from him. The history was as follows:-For the last sixteen years he had been a carpenter, serving with a brigade of artillery in India. Up to three years ago he had always enjoyed good health, but had been a constant and free drinker. He stated that he had never had syphilis. During the Afghan campaign he received a bullet wound on the right side of the sagittal suture, extending from the coronal suture in front to the lambdoidal su ture posteriorly. The wound healed rapidly, but was complicated six weeks later by the formation of an abscess, which was opened antiseptically under chloroform, but he does not know whether any bone was removed. On being discharged from hospital he drank heavily, and in one of his bouts of intoxication he lay down in a marsh, where, becoming insensible, he was picked up and transferred to the hospital suffering from sunstroke. He remained under treatment for three months, and ever since had been troubled with pain and lightness in the head, numbness and weakness 